\title{
Environmental Policy, Innovation and Transformation: Affirmative or disruptive?
}

\section{Contents}

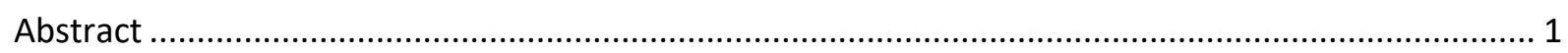

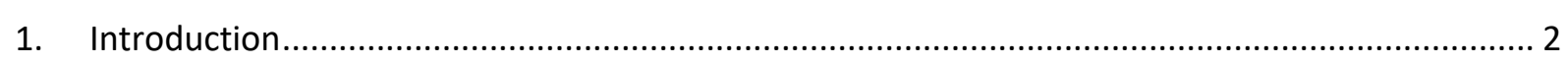

2. Evaluating Effectiveness of Environmental Policies .................................................................. 2

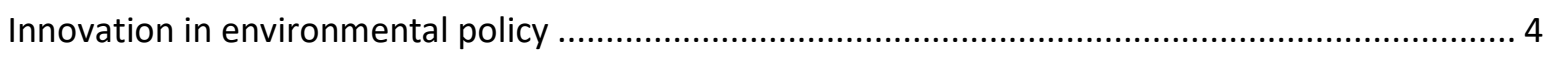

Limited environmental policy integration as an obstacle to effectiveness ...................................... 4

Spatial and temporal dynamics of environmental policies ......................................................... 6

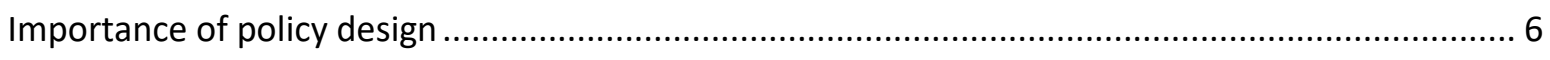

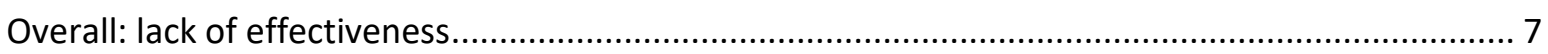

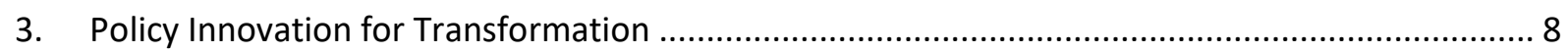

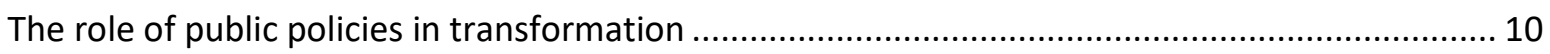

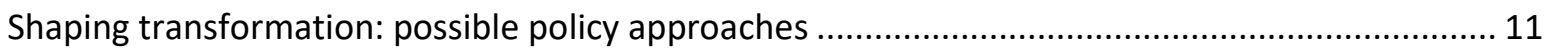

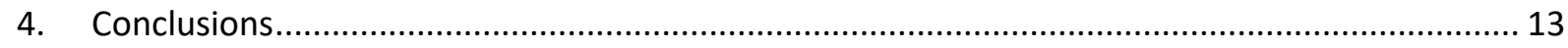

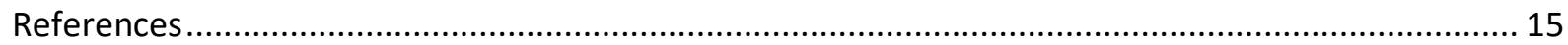

\section{Abstract}

The paper firstly summarizes the approach and findings to evaluate the effectiveness of environmental policies around the globe as it was undertaken in the Sixth Global Environment Outlook (GEO-6; 2019). The data gathered in GEO-6 reveals (1) a high level of institutional innovation, increasingly from the global south, (2) a lack of environmental policy integration (3) spatial and temporal dynamics and (4) the importance of the policy design. Current environmental policies are, however, not sufficient to effectively preserve natural resources and limit emissions to a sustainable level. This has led to a general recognition of the need for a transformative change that goes beyond mere improvements of efficiency. The second part of the paper analyses how environmental policies could contribute in shaping such transformations to sustainability. Transformative policies can be built on social innovations and experimentation with institutional innovation. This is compatible with incremental and sectoral policy making. However, given the complexity and stability of social systems, the outcomes of such policies are uncertain. This is why we argue for strengthening conventional, strategic environmental policies and complementing rather than replacing them with transformative policies. 


\section{Introduction}

Achieving sustainable development implies transformative change of current economic and technological systems that serve the needs of society. There is considerable scientific evidence supporting such a conclusion: efficiency improvements are limited, and rebound and growth effects from increasing income and growing population result in increasing emissions, resource use and pressure on the environment. In response to this evidence, one of the most comprehensive recent expositions of which was UNEP's sixth Global Environment Outlook (GEO-6, UNEP 2019a), politicians, business and civil society are increasingly calling for far-reaching changes in society's systems and patterns of production and consumption.

GEO-6 is an integrated global assessment of the state of the environment and the prospects for the future. It is based on the state of knowledge from various disciplines on the state of the environment, presenting the most recent scientific information and analysis about water, air, soil, biodiversity, the oceans and a number of cross-cutting issues. The report is mandated by the UN Environment Assembly (UNEA) and involved around 150 authors and over 1000 reviewers, coordinated by UNEP. The Summary for Policy Makers (UNEP 2019b) was negotiated and agreed by representatives of around 100 countries. The report was presented to UNEA in March 2019. Both authors were involved in drafting the assessment.

One of the innovative features of GEO-6 compared to earlier GEOs is the evaluation of policies - it contains an analysis of the nature, characteristics and effectiveness of environmental policy in different countries to date. GEO-6 contained extensive empirical analysis on environmental policy making, and in its relation to policies in other areas.

An important ambition of GEO 6 was to describe the landscape of policy responses to the overuse of natural resources, unsustainable level of emissions and the resulting degradation of natural systems. Furthermore, the question posed to the authors of the report was to evaluate the effectiveness of these policies. In the mandate for GEO- 6 as adopted by UNEA, the representatives of countries asked for a quantification of the effects of policies.

\section{Evaluating Effectiveness of Environmental Policies}

Unlike previous GEO reports which focused on the state of the environment, and scenarios for future development, much emphasis was given to the responses to the changes in the natural environment being wrought by human activities. In the following, we summarize the approach and findings of the evaluation of policies in GEO-6.

While it is not possible to evaluate all environmental policies across the world, the report analysed the effectiveness of environmental policies using a sample of case studies and indicators within a common evaluative framework. The gold standard for evaluating the effectiveness of policies would the comparison of the with-policy situation with a similar situation without such a policy. This may be an experimental setup, a comparison over time or with other countries, or the construction of a counter-factual scenario. However, given the complexity of the socio-technical systems being addressed by environment policies and the great many intervening variables that influence such systems, it is usually very challenging, if not impossible, to identify a situation that is fully comparable to the situation with a policy in place.

This is why policy evaluation usually takes a theory-based approach: based on findings on variables that had proven to be relevant for effectiveness in other situations, a theory-based evaluation searches for such factors and suggests causal chains proceeding from the policy to an impact (output-outcome-impact chains). This is the approach taken in GEO-6. The assumption is that if a 
policy has certain procedural and design features, it is likely to be effective. This picks up on the arguments on effectiveness of environment policies, distinguishing between procedural effectiveness and substantive effectiveness (Emerson and Baldwin 2019).

The academic literature, including what has been contributed over the years in JEPP, is rich in suggesting such features, and underpins the respective arguments with empirical findings. For example, some contributions argue for reflexiveness of environmental policies, e.g. by applying experimentalism in policy design (van der Heijden 2015) or by the use of appraisals and indicators (e.g. Howlett and Cuenca 2017, Meadowcroft and Steuerer 2018). Others argue environmental policies should be innovation-oriented (e.g. Schubert and Sedlacek 2005), participatory (e.g. Kostka and Mol 2013, Pomeranz and Decker 2018), coherent with other policy goals (e.g. Huttunen 2015), and based on ambitious goals (Wolff et al. 2017). Other contributions aggregate various features to principles of good governance (e.g. Pomeranz and Stedman 2020, Meadowcroft 2007).

Based on these and additional references on effectiveness of environmental policies and governance, the policy design literature, and the literature on environmental policy integration, in total 13 criteria for effective policies were identified against which cases of environmental policies can be evaluated. The criteria were operationalized as guiding questions for the appraisal of policies:

1. Effectiveness/goal achievement - What effects did the policy have on the targeted problem?

2. Unintended effects - What were the unintended effects of this policy?

3. Baseline - Was the baseline defined at the policy design stage?

4. Coherence/convergence/synergy - How does the policy intersect with other related policies?

5. Co-benefits - Did the policy design provide for co-benefits?

6. Equity/winners and losers - What are the effects of this policy on different population groups?

7. Enabling/constraining factors - What external factors are likely to influence the intended policy effects?

8. Cost/cost-effectiveness - What were the financial/ economic costs and benefits of this policy? Is it the most cost-effective or the least-cost approach?

9. Time frame - Was the policy implemented within the expected time frame?

10. Feasibility/implementability - Is the policy technically feasible in the institutional context?

11. Acceptability - Do the relevant policy stakeholders view the policy as generally acceptable?

12. Stakeholder involvement - To what extent were affected stakeholders actively involved in implementation?

13. Any other factors - such as transformative potential, intergenerational effects, transboundary impacts, sociocultural concerns, political interference, enforcement issues, compliance with legal standards (e.g. national/ international human rights)

(UNEP 2019a, p. 278).

For each of the thematic issues of GEO-6 (air, water, oceans, land, biodiversity) classes of typical policy responses (e.g. market-based instruments, planning, command and control, etc.) were identified, together with concrete examples of these governance approaches. Cases for an in-depth evaluation were selected to cover a broad diversity of issue areas, governance approaches and a wide regional coverage. Given the large number of environmental policies in place, it was not possible to have a complete or representative sample for the analysis. In total 23 case studies were chosen to illustrate a wide range of policy types and were analysed in detail.

To address the shortcomings of a qualitative case study approach, the evaluation was complemented by an indicator-based approach: for the different issue areas, indicators were identified for which a 
causal link to policies can be made, and for which ideally data is available across time and at a country level. The indicator-based approach has shortcomings as well, as it cannot account for the possible intervening variables. However, together with the fine-granular but selective case studies, the analysis provides a broad picture on the global state of play in environmental policies.

The findings of the evaluation are summarized in the following.

\section{Innovation in environmental policy}

The analysis of the 23 case studies in GEO- 6 demonstrates a high level of innovation in environmental policy across the globe. New institutions, policies and policy instruments have been developed and introduced all over the world. Policies are developed that go beyond technical fixes by increasingly addressing social and economic practices. Innovation is not limited to the western industrialized countries, instead more and more policy innovation come from emerging economies and developing countries (UNEP 2019a, p.454). In these countries, environmental issues are often linked to social issues: environmental policies are at the same time aiming for reduction of emissions and resource depletion, as well as for an eradication of poverty or access to goods and services for the poor. Examples include the management of fish in Chile with a privileged access to fishing rights for small fishers (UNEP 2019a, p. 356 f.), access to drinking water in South Africa with progressive pricing (UNEP 2019a, p. $410 \mathrm{f}$.), or programmes to distribute efficient lightning to the poor in rural areas in India (UNEP 2019a, p. 439).

Environmental policies aim to encourage behaviour change or limit choices of consumers, enterprises, communities towards reducing emissions and resource depletion. The case studies demonstrate the utilisation of different modes of interventions: persuasion, regulation or economic incentives. There is no evidence for a trend towards a specific class of policy instruments. For complex environmental problems, there is no single best instrument, but policy mixes are more effective, often combining different modes of governance that mutually reinforce each other (hybrid governance) (e.g. the strategy to reduce food losses in Japan (UNEP 2019a, p. 434)). For example, combining labelling with taxation of environmentally harmful consumption on the demand side with limit values for emissions on the production side can mutually reinforce and create markets for environmental innovation (UNEP 2019a, p. 454).

In many cases, policy instruments were designed with a rather indirect intervention. For example, environmental policies instead of introducing direct regulation by setting limit values or environmental taxes rather establish processes which enable and encourage actors to reflect on their environmental performance, e.g. environmental impact assessments, planning procedures or environmental management systems (e.g. reporting scheme on freshwater use in the mining sector of Australia (UNEP 2019a, p. 412 f.), or the marine litter management plan in the Mediterranean (UNEP 2019a, p. 353 f.). Such governance approaches are particularly difficult to evaluate in their effectiveness.

\section{Limited environmental policy integration as an obstacle to effectiveness}

The use of resources and emissions is not determined by environmental policies and institutions only, but are shaped by other sectoral policies, e.g. for housing, infrastructure, agriculture, industry, energy, etc. Therefore, the integration of environmental concerns in these sectoral policies is a necessary feature of policies in these areas, albeit a difficult one to realise, for policy to lead to substantial environmental improvement. The analysis of GEO- 6 showed that global public policy to date had not yet been successful in respect of such integration.

Effective and ambitious environmental policies are often contested by the affected sectors and their respective institutions within governments. Their design, and the level of ambition, are usually a 
subject of negotiation in the policy process, during which environmental actors usually need to find compromises. As a result, it is often second-best environmental policies that are adopted. As a result, for many issue areas and in many countries, environmental policy does not make use of (potentially powerful) mixes of price signals and regulation. Instead, mechanisms of persuasion, self-regulation or subsidies are introduced. Often, vested rights and interests are not touched, but environmental policies focus on new products or sites, e.g. in permitting procedures for development projects. A lack of coherence with other policy domains was reported among others for the management of the Great Barrier Reef (UNEP 2019a, 351 f.), the Management of Marine Litter in the Mediterranean (UNEP 2019a, p. 353 f.), regulation of exhaust gases from cars in Europe (UNEP 2019a, p. 308 f.) or the ASEAN agreement on transboundary haze (UNEP 2019a, p. 314).

Although there is no systematic evidence on the uptake of environmental goals in sectoral policies such as agriculture, transport, urban planning, or water, the case studies suggest that comprehensive environmental policy integration has rarely been achieved in practice. This applies to all regions - industrialized countries perform no better than emerging and developing economies and all domains of environmental policies.

Broadly, there are two approaches to support environmental policy integration (EPI): in the first, institutions are introduced that encourage sectoral policy makers to take environmental concerns into consideration or that enable environmental actors to have a say in the policy process. Institutional approaches include various assessment procedures (e.g. integrated regulatory impact assessment with a focus on environmental aspects or strategic environmental assessments). Many countries (and some international organisations) have begun to adopt such approaches/instruments to assess the potential impacts of proposed legislation not only on economic, but also on social and environmental impacts (Radaelli 2009; Jacob et al. 2011; Adelle and Weiland 2012; Adelle et al. 2016). However, in the case studies analysed, such tools were not used at all, or did not play a significant role in the design or the evaluation of the policies. Despite the frequent call for evidencebased policy making, in order to legitimate policies and enhance their acceptance, environmental policy making appears not to apply these tools to their full potential (UNEP 2019a p. 455). This refers both to ex ante assessments as well as to ex post evaluations. Most often, the evidence base on the effectiveness of policies is rather thin, and environmental policy making is rather like steering in the fog.

Besides institutional approaches, a second approach to EPI involves demonstrating the economic and social benefits of protecting the environment and a sustainable use of natural resources. This may be additional economic growth from innovation, savings from conservation of natural resources, and avoided costs of environmental damage. By this, common narratives and coalitions with actors from economic sectors are sought to advance environmental objectives and to integrate environmental concerns in other policy domains. For example, UNEP estimates that $2 \%$ of global GDP in green investment would deliver long-term economic growth while minimising adverse impacts of climate change, water scarcity, and the loss of ecosystem services (United Nations Environment Programme [UNEP] 2011). Similar assessments and strategies focusing on utilising economic benefits are developed in all regions of the world. Many countries of the global south have undertaken Green Jobs assessments, e.g. Tunisia, India, Uruguay, Mexico, and others (ILO 2020).

Both for institutions that were introduced to enhance EPI (e.g. interdepartmental working groups, strategies, reporting requirements etc.), as well for strategies focusing on socio-economic benefits, there is little evidence on the actual outcomes of policy integration and few attempts to measure the level of policy integration. Among the few exceptions is the PEER project (Mickwitz et al. 2009) which assessed climate policy integration in Europe, at multiple scales. The findings reveal a higher level of 
integration among cities and municipalities in their strategies and plans compared to their national governments. Such multilevel governance approaches to EPI is yet another challenge in terms of attributing effectiveness. They are, as shown in the following section, a source of innovation and diffusion for environmental policies.

\section{Spatial and temporal dynamics of environmental policies}

The evaluation of environmental policies in the GEO reveals, on the one hand, a dynamic of increasing stringency over time and, on the other hand, a dynamic resulting from the diffusion between regional entities. In many cases, environmental policy objectives were initially introduced with a low binding effect, e.g. as persuasive instruments, and with ambitious targets. By demonstrating their technical, social and economic feasibility, and by creating markets for environmentally friendly alternatives, new opportunities and capacities for advancing environmental policies are created. Environmental policy objectives are made more ambitious and stricter policy instruments are selected. Soft instruments pave the way and contribute to the build up of capacities which enable the introduction of regulatory or market-based instruments. Although this is not automatic, and other factors are required to open up a window of opportunity, there is evidence of policy learning, and the level of ambition increases, over time. In a few cases, this is part of the policy design from the very beginning. The so-called ratchet mechanism of the Paris Agreement, the commitment to continuous improvement of policies over time, could be applied much more often than is the case today. However, positive feedback mechanisms are rarely an integral part of environmental policies and tend not to be deliberately applied in the policy design.

Another dynamic of environmental policies is policy diffusion across jurisdictions and across the different levels of governance. The example of pioneer countries is taken up and adapted to other countries, communities or regions. Such country to country learning is supported by regional and international organisations, including EU, OECD or UN through facilitating peer-to-peer learning as well as being the subject of development cooperation. Some publicly available datasets aim to facilitate charting the diffusion of environmental policies, particularly on climate change and renewable energy policy. The London School of Economics' Climate Change Laws of the World Database (Grantham Research Institute on Climate Change and the Environment 2017), for example, compiles information on national-level climate policies ranging from adaptation to mitigation to transport. Similarly, REN21's Global Status Report (REN21 2017) charts the use of renewable energy policies across a large sample of national and subnational jurisdictions.

However, despite prolonged interest in the topic and efforts to provide systematic policy information, knowledge of the spatial diffusion of environmental policies, especially outside the specific policy field of renewable energy, remains limited. Although policy diffusion appears as a positive mechanism for policy learning across different jurisdictions, often facilitated by international regimes and multi-level governance, there is evidence that less ambitious policies (e.g. distributional rather than re-distributional policies) are more often the subject of policy diffusion (Busch and Jörgens 2005). Furthermore, there is lack of research on the role of contexts for the effectiveness of policies adopted from abroad.

\section{Importance of policy design}

The GEO policy evaluation revealed a wide range of different policy instruments and governance approaches to address environmental concerns. Examples of regulatory command and control policies, environmental taxes, subsidies, emission trading, planning, labelling, private regulation, and network management indicate the wide range of approaches. Based on the GEO findings, there is no uniform trend towards specific types of instruments, instead a diversification of instruments. Most important, the type of instrument is not sufficient to explain effectiveness. There is considerable 
evidence that policy design is (at least) as important as policy instrument choice for effectiveness of individual policies and policy mixes (Yin and Powers 2010; Flanagan, Uyarra and Larania 2011; Kemp and Pontoglio 2011). The importance of good policy design for the effectiveness of environmental policies cannot be overstressed. Some common elements are:

(i) setting a long-term vision and avoiding crisis mode policy decisions, through inclusive, participatory design processes;

(ii) establishing a baseline, quantified targets, and milestones;

(iii) conducting ex ante and ex-post cost-benefit or cost-effectiveness analysis to ensure that public funds are being used most efficiently and effectively;

(iv) building in monitoring regimes during implementation, preferably involving affected stakeholders; and

(v) conducting ex-post evaluation of the policy outcomes and impacts to close the loop for future policy design improvements.

However, the GEO-6 case studies demonstrate that such features are largely underused or even not applied at all. For example, among the 23 case studies, there is none, which applies ex ante impact assessment to its full potential. Thereby, potential co-benefits with other policy areas, including economic and social benefits may not be utilized to their full potential. Ex post evaluation is rarely foreseen and even less often undertaken. The findings from the evaluation demonstrate that environmental policy making is to a large degree based on incrementalism instead of long-term strategic policy making. A transparent participation of non-governmental actors is missing in many cases - which opens up opportunities for lobbying and intervention to lower the level of ambition.

\section{Overall: lack of effectiveness}

The GEO- 6 case studies show that, across the various issue areas, environmental policies do not sufficiently address the drivers of environmental change. In addition to the lack of policy integration into non-environmental sectors and the often poor design of policies, the lack of administrative capacities to actually implement strategies or limit values for emissions, product standards, etc., remains a serious obstacle to the effectiveness of environmental policies. This lack of capacities is a further constraint on the effectiveness of environmental policies.

The lack of effectiveness is reflected in the evaluation in GEO- 6 based on indicators. Insofar as these indicators report on policy outputs and outcomes (e.g. number and size of protected areas), there is visible progress. Insofar as they report on impacts (e.g. land use, air quality, biodiversity), it can be shown that drivers of environmental change are not yet effectively addressed. The distance to goals suggests that environmental policies are not yet sufficiently effective to achieve sustainable development.

It can be concluded that the agenda of environmental policies - limiting resource use and emissions by effectively addressing the behaviour of consumer, business, communities, enabling innovation, and strengthening of environmental actors - is far from completed. Notwithstanding the considerable dynamics in environmental policies, "soft" policy instruments prevail, there is a lack of capacity for their implementation, and a lack of environmental policy integration remains a serious problem. The analysis of indicators of policy effectiveness indicates that the efforts and successes of environmental policy are overcompensated by growth effects.

Against this background, a change in the environmental policy discourse is emerging: in addition to striving for improvements within the given economic, technical and social systems and their development paths and avoiding or limiting the environmental impacts of these systems, ways are 
being sought for a fundamental economic and social reorientation. This reorientation becomes clear with the claim of a need for transformative change. What does this imply for policy making?

\section{Policy Innovation for Transformation}

Rebound and growth effects counteract incremental reductions in emissions and resource depletion (e.g. Rennings 2014, Dimitropoulos et al. 2016). Rebound effects bring about an increase in demand for a given service or product resulting from cost reductions because of efficiency improvements. Such effects are particularly observed for technologies that increase energy efficiency. Growth effects are evident in an increase in overall demand for goods and services (and related emissions and resource use) resulting from increases in incomes (Semmling et al. 2015). Regardless whether it is rebound or growth effects, a strategy based on efficiency improvements by environmental innovation only is not sufficient to achieve a sustainable use of natural resources because it does not address the root causes of over-depletion of resources and exceedance of planetary boundaries. Comprehensive transformations are called for that not only address technologies, but socio-technical and socio-economic systems as a whole (e.g. Geels 2002, WBGU 2011).

Socio-technical and socio-economic systems are specific configurations of technologies, products, infrastructures, markets, social practices, related institutions and cultural values to serve the needs and wants of society (Geels 2002; Grießhammer and Brohmann 2016). Examples of socio-technical or socio-economic systems are the systems for energy, nutrition, health, education, communication or mobility. A transformation of such systems would provide services to society in a fundamentally different way. This is not limited to technologies (although technological innovation can be considered as a starting point in many examples of transformations), but also entail changes in social practices and cultural values. The conceptions of normality in institutions, infrastructures, and markets is transformed. Transformations often (not always) enable new actors to replace the incumbents in providing services to society. In a nutshell: transformation can be considered as a passage from one dominant techno-socio-economic regime to another.

Transformation results from the inability of a system to innovate and adapt to changing contexts and demands. This inability may occur at the end of a technological paradigm when the various options for new products and cost reduction has been exploited (Kondratieff 1926, Schumpeter 1942, Jänicke and Jacob 2013). When this takes place, the time is ripe for replacing the existing technological paradigm and starting a new long-term innovation cycle. A different example is the political transformation in socialist countries in the late 1980s resulting from their inability to fulfil the demands of their societies.

The dominant socio-technical and socio-economic systems have not yet found an adequate response to climate change, loss of biodiversity, scarcity of natural resources, pollution and related health problems. This may result in a sustainability transformation. Such a transformation would not only be characterised by the underlying crisis, which triggered the transformation, but would also entail a change of normative orientation. The concerns of sustainable development would become embedded in cultural values, institutions and social practices.

Transformation is not only defined by the object and direction of change, but also by the specific process of change. Transformative change is different from the regular process of innovation. Transformative change starts from (technical, social and institutional) innovations that are established in niches (Schot and Geels 2008). They are developed within networks outside the established structures. Transformative innovations and the niches in which they are established entail a vision of an alternative system configuration to provide services to society, rather than promising a mere improvement of the existing status quo. 
In the beginning of a transformation there is, however, no dominant alternative vision, but rather competing visions for an alternative system configuration. The current competing views on sustainability in agriculture may serve as an example. Some actors favour a regionalized, small-scale ecological agriculture, others a high-tech agriculture in glasshouses powered by solar power and production of in-vitro meat, largely detached from natural systems, and yet others envision urban farming as a pathway towards a sustainable agriculture. All of these visions are meant to replace the current agricultural system; however, they follow contradictory and competing pathways. All of these visions not only imply technological improvements of the existing system, but a replacement of the current system including their institutions, infrastructures, and social practices. Similar competing visions can be demonstrated for the energy sector (e.g. decentralized vs. centralized renewable energy), or mobility (e.g. autonomous, battery-powered mobility versus mobility based largely on public transport, etc.).

These innovations are realized, implemented and tested in niches. By means of demonstrating the feasibility of alternative system configurations, and in combination with the inability of current systems to adequately adapt to changing contexts, the legitimacy of the existing systems and their dominance is put into question. The alternative system designs and the established designs are the subject of competition and conflict: actors representing the incumbent systems contest the claims that their services could be provided by alternative means. However, niches that successfully attract imitators or users and that are able to scale up their innovation, counter such arguments.

Once a critical mass of applications has been reached, network effects are created, or once institutions are established that stabilize the niches, the pace of transformative change is accelerated. This is particularly the case once a co-evolution with other elements of a system begins. If an innovation and its diffusion changes the framework conditions for another element of the given system, and thereby positive feedback loops are established, innovation co-evolves in e.g. infrastructures, markets, institutions or social practices. Such positive feedback mechanisms have been demonstrated for institutions, technology and markets of renewable energy technologies (Jänicke and Rennings, 2011): policies that promote renewable energy create markets for such technologies, which stimulate technological innovation, and market growth and demonstrated feasibility of innovation create demands for new policies. As a result, the level of policy ambition coevolves with markets and technological advances.

Once such critical moments have been passed, a vision for an alternative system configuration is shared by an increasing number of actors, and gains acceptance. Such a shared vision delegitimizes current practices and systems. A widely accepted alternative vision provides guidance and directs the innovation processes, it coordinates actors and their activities and creates network effects and it legitimizes institutions that support the scaling up of an alternative configuration. Hitherto accepted modes of production and consumption become culturally stigmatized and social practices are adapted to the new system. Accordingly, the rate of change accelerates.

As a result of this acceleration, existing practices, technologies, structures and the related actors are questioned as to their legitimacy and suitability to provide their services to society. The dominant technologies and structures become subject to 'exnovation' - "the purposive termination of existing infrastructures or technologies" (Heyen et al. 2017, p. 329). An example is the divestment movement from fossil fuels or (in many cases sudden) shifts in consumer preferences.

A transformation comes to an end once the alternative system configuration is established and accepted as normality. The intensity of innovation and diffusion flattens back to a normal level and new institutions, technologies, social practices, infrastructures, etc. are in place. Innovation takes place, but again as incremental improvements rather than disruptive innovation. 
To summarize, transformations are characterised by:

- Sudden and disruptive system innovation. Socio-technical or socio-economic systems are reconfigured in a way that provide for societal needs in a fundamentally different way. A sustainability transformation is characterised by the underlying problem structure and its normative orientation.

- Transformation starts from (competing) visions that suggest alternative system configurations. Innovation (including social and institutional innovation) occurs, taking place and being tested outside the current system.

- In early phases, the process of innovation is undirected. Only once a vision for an alternative system configuration is widely accepted and co-evolutionary processes take place, transformation gains momentum and direction.

- Transformation typically implies that new actors (and their practices and structures) replace the incumbents.

- Ultimately, it is characterised by the phasing out of an existing system configuration.

GEO-6 examined the current level and role of bottom-up initiatives for sustainable development. Through a combination of a crowd-based platform where proposals for sustainability initiatives could be submitted, participatory workshops in different regions of the world and an analysis of platforms for bottom-up initiatives, tens of thousands of examples were identified that aim at the implementation of sustainability goals. These are developed and carried out by companies, local authorities and civil society. As with policy innovations, the analysis shows that innovation is not limited to rich countries alone, but that such initiatives can be found in all regions of the world (UNEP 2019a, pp. 552ff.). However, the analysis also finds that a supportive political framework has been lacking to date. This would include both enabling conditions (establishing and supporting markets for innovations, supporting experiments, financial resource mobilization, human resource mobilization) and disruptive conditions (control policies, rules reform, reduction in existing regime support, changes in networks and key actors) (UNEP 2019a, pp. 573ff.).

\section{The role of public policies in transformation}

What is the role of public policies in the context of a transformation to sustainability? At first sight, public policy-making to govern transformation appears as an excessive demand. Policy-making is incremental and fragmented. Policy-making, at least in western liberal democracies, is not supposed to be prescriptive on social practices and cultural norms. The different domains of public policymaking are integral parts of socio-technical and socio-economic systems rather than being in a position to actually exert control over such systems. Increasingly, socio-technical and socio-economic systems are organized beyond the scope of jurisdictions, spanning from the local to the national, European and international level. Against this backdrop, a holistic and strategic approach to the governance of such systems appears unrealistic, if not undesirable.

Theories of political process underpin the doubts about the ability of public policies with regard to steering socio-technical and socio-economic systems. An often quoted and empirically well underpinned conception of policies and policy-making processes describes the process as muddling through and incrementalism (Lindblom 1959, Knaggård 2014). Since there is no central planning possible (and any attempt to provide such overall planning necessarily fails as there is no complete knowledge of the side effects of such planning), policy-making is a stepwise trial and error process. There are good reasons for incrementalism, including flexibility and avoidance of conflict. Muddling 
through implies that there is no central planning agent, but policies are negotiated between independent actors. Other theories that focus on institutions as constraints for policy makers underpin expectations of limited capacities to actually govern societal systems (e.g. Mayntz and Scharpf 1995). Similarly, theories that focus on power and interest (e.g. Maeße 2013) or policy learning (e.g. Lindberg 2013) would not expect disruptive system innovation and transformation to result from public policies. Instead, public policies would maintain the current configuration and focus on incremental innovation within the given framework.

Authors advocating transformation to sustainability mirror this perception of rather weak and affirmative public policies. In their view, states and public policies are part of the incumbent regime and rather inhibit transformative innovation. Such innovation takes place outside state actors, it emerges from society and is constrained by governmental actors rather than being promoted by them (e.g. Welzer and Leggewie 2010). In this view, public policies and related institutions are an object of transformation rather than causal of transformative change. Public policies constrain niche innovations rather than promoting and enabling them, and niche actors rather prefer to be independent from governmental regulation and subsidies.

While there is certainly evidence for such a view, there are at the same time governmental actors, programmes and institutions that are actually interested in promoting transformation,and are critical of the fragmentation of governments and incoherence of policies. While there are institutions that promote and protect the different sectors of the economy, infrastructures, housing, mobility, consumption etc. there are at the same time institutions that question the current configuration. Policy entrepreneurs within the public administrations, political parties, parliaments etc. continuously seek for policy innovation and compete for attention and approval. This process can be understood as an evolutionary model of public policy (Cairney 2013), a creative process whereby policy entrepreneurs search for the right moment in time for the adoption of their ideas (Kingdon 1995). Evolutionary theory would also imply that rapid and substantive policy change is possible as a result of a punctuated equilibrium (Baumgartner and Jones 2009). On such occasions, a third-order change is possible that goes beyond incremental improvements (Hall 1993). Cairney (2013) suggests combining theories of evolutionary policy-making with complexity theory to explain the possibility of far reaching changes. Although this has not yet been fully exploited in empirical studies, it seems to be a promising starting point for developing policy options for shaping transformation.

The typical process of transformations, and their evolutionary character, open up some options for action for actors that enable or actually shape socio-technical and socio-economic systems even within the constraints of public policy-making. An evolutionary understanding of the policy process does not demand a fully integrated, holistic and reflexive long-term political strategy for transformation, which seems rather unrealistic. Instead, a policy approach based on incremental trial and error has a high affinity with the evolutionary process of transformation as depicted above.

\section{Shaping transformation: possible policy approaches}

Given the processes of transformation as depicted above and the role of system innovation (including social and institutional innovation), the complexity of socio-technical and socio-economic systems, and the constraints and opportunities of public policy-making, the following spheres of activity could be exploited in order to shape transformations to sustainability.

Firstly, a priority would be to establish a knowledge base for transformation. Given the importance of social and institutional innovation in niches for transformation, this would include systematic surveys on social innovation and trends. Furthermore, integrated assessment of a given system and the exploration of potential scenarios for an alternative configuration would contribute to this. In order to develop socially robust knowledge that would be accepted as a basis for decision-making and that 
would provide legitimacy for policies, it is necessary to involve stakeholders in the process of the assessment. This is good practice for international assessments and the involvement of policy makers (Kowarsch 2016).

Secondly, and in the same vein, programmes to support social innovation could be developed to complement existing innovation policies. The need for innovation policies is widely accepted, as economic actors lack incentive to invest in research and development. Given the payoffs from innovation for society, it can be justified to invest public funds in subsidies for innovation. So far, innovation policies largely focus on technologies. Social innovation has similar potential for payoffs for society, and similar costs and risks for individuals. From the viewpoint of their importance for transformation, in particular those (social and technological) innovations that entail an alternative vision for a system configuration could be promoted. As the success (in terms of technical feasibility and acceptance) of such innovations cannot be predicted, a policy that promotes transformative social and technical innovation would rather aim for developing a pool of innovation instead of focusing on a single solution and picking a winner. Such a programme could be coined as a transformative innovation policy (Chataway et al. 2017).

Thirdly, policies and regulation could be developed and applied in an experimental mode. Institutional innovations are key for transformation. However, with current incremental policymaking it is unlikely that policies would be introduced that are disruptive for the current systems configurations. Actors from within the political system would object to such approaches. In the framework of simulation games, policy labs (e.g. open policy-making in the UK, EU Policy lab, etc.) or regulatory innovation zones (e.g. Bauknecht et al. 2015) experimental policy-making can be undertaken. Very much as is the case for social and technological innovation policies, a pool of institutional innovation seems desirable rather than betting on a single policy. This implies that policy coherence is not necessarily an aim for a transformative policy.

Fourthly, visions of alternative system configurations can be the subject of policy making. Such visions are powerful to legitimize niche innovation and public policies. They can be understood as desirable future states of society (John et al. 2015; Wiek und Iwaniec 2014). They are key for processes of transformation (Loorbach 2010; Jacob et al. 2020). The development of visions is a wellestablished part of strategies and planning processes (Wiek und Iwaniec 2014, Jacob et al. 2015). However, it has been pointed out that there are limitations to the actual shaping of visions and related processes (SRU 2016), not least due to the multiplicity of actors, norms, discourses, technologies, institutions (Brand 2016). Visions are contested and diverse. This is the case with current debates on sustainable development: is this to be achieved by post-growth or by green economy? By efficiency or sufficiency? Centralized or decentralized? While governmental actors are not able to prescribe societal visions, they are certainly relevant actors in their development and perhaps even more important - can provide venues and processes for actors to meet.

Fifthly, yet another action area is the development and enabling of new actors. Transformation research suggests that it is typically innovators from outside the existing systems that establish niches and initiate transformative processes. The existing actors (incumbents) tend to prefer incremental improvements and to avoid a devaluation of their investments. Therefore, a transformative policy would enable new actors to provide services, if not create them.

Finally, and certainly most demanding are policies that would organize the phase-out of existing structures. This 'exnovation' (Heyen et al. 2017) highlights that beyond innovation there is a need to replace unsustainable structures that remain in operation despite the demonstrated feasibility of alternative configurations. There are many examples of innovation that are taken up by economic structures without altering production or consumption. Innovations are taken up by mainstream 
business through diversification: e.g. electricity from renewable energy is provided alongside electricity from coal and nuclear; organic food is produced alongside conventional food; batterypowered vehicles are produced together with resource-intensive SUVs. Frequently, conventional products are maintained by subsidies or by increasing exports when they face challenges from innovation. Other forms of adapting to system innovation are hybrid forms: old and new technologies, practices and institutions are mixed. Both old and new systems operating at the same time as well as hybrid forms may lead to the situation that environmental performance during a transformation is even worse than in the phases of relative stability before and after a transformation.

To summarize, a transformative environmental policy that aims to shape transformation towards sustainability in a context of countervailing actors, interests, institutions and power within and beyond government has a number of options. These options mirror typical phases and causalities of past transformations:

- Creating a knowledge base through surveying and assessing social and institutional innovation and trends, and integrated assessments

- Complementing innovation policies through the promotion of social innovation

- Developing a pool of institutional innovation through regulatory experimentation

- Initiating and moderating the development of visions for alternative system configuration,

- Supporting actors who provide services to society in an alternative configuration,

- Organizing the exnovation out of incumbent systems.

The proposed options for action for shaping transformation towards sustainability build on the process of transformation. They acknowledge the limitations of public policies in actually steering complex systems. Stepwise, through creating a knowledge base, promoting transformative innovation and the actors supporting such innovation and ultimately phasing out of incumbents, a build-up of capacities is pursued.

While there is a considerable rhetoric on the ambition to establish transformative policies, so far, there are rather few examples that actually aim to support disruptive change. GEO-6 policy evaluation shows that environmental policy making is rather in an incremental mode of efficiency improvement, than an orientation towards transformation to sustainability.

\section{Conclusions}

Although innovation-oriented environmental policies have considerable potential in reducing emissions and resource depletion that is as yet underexploited, a strategy based on efficiency improvements is not sufficient for achieving a sustainable development. The decarbonisation of the economy and society, the effective protection of biodiversity, a circular economy based on renewable raw materials and without waste, the limitation of nitrogen emissions from agriculture, and other pressing environmental problems certainly cannot be effectively solved by end-of-pipe measures or efficiency improvements.

Unsustainable production and consumption patterns are deeply rooted in complex socio-technical and socio-economic systems. Addressing their systemic nature, including relevant institutions, social practices, infrastructures, culturally embedded values and norms, implies a fundamental transformation of such systems. Social practices, cultural norms, the institutional and infrastructural embedding of resource depletion and emissions have not yet been the subject of environmental 
policies. Given the autonomous, co-evolutionary and emergent character of such systems on the one hand, and the limitations of environmental policies on the other hand, a top- down planning and strategic steering of such systems is unrealistic.

The evolutionary character of transformation processes opens up opportunities for public policy making even within the constraints of fragmentation and incrementalism. Policymaking could make use of societal trends and innovation, of visions or experimentation, to a much greater extent than is the case today.

Such policies should not, however, replace current environmental policies, but rather be developed and applied as complementary approaches. In view of the urgency of addressing environmental problems, it would be a risk to wait for transformative innovation and change. Processes of transformation have an enormous potential to reshape societies, but the difficulty of actually initiating, steering and re-directing societal systems imposes a risk for policymaking. Conventional environmental policy making therefore still has an important role, especially as potentials for ecoinnovation and efficiency improvements are still very far from being fully exploited.

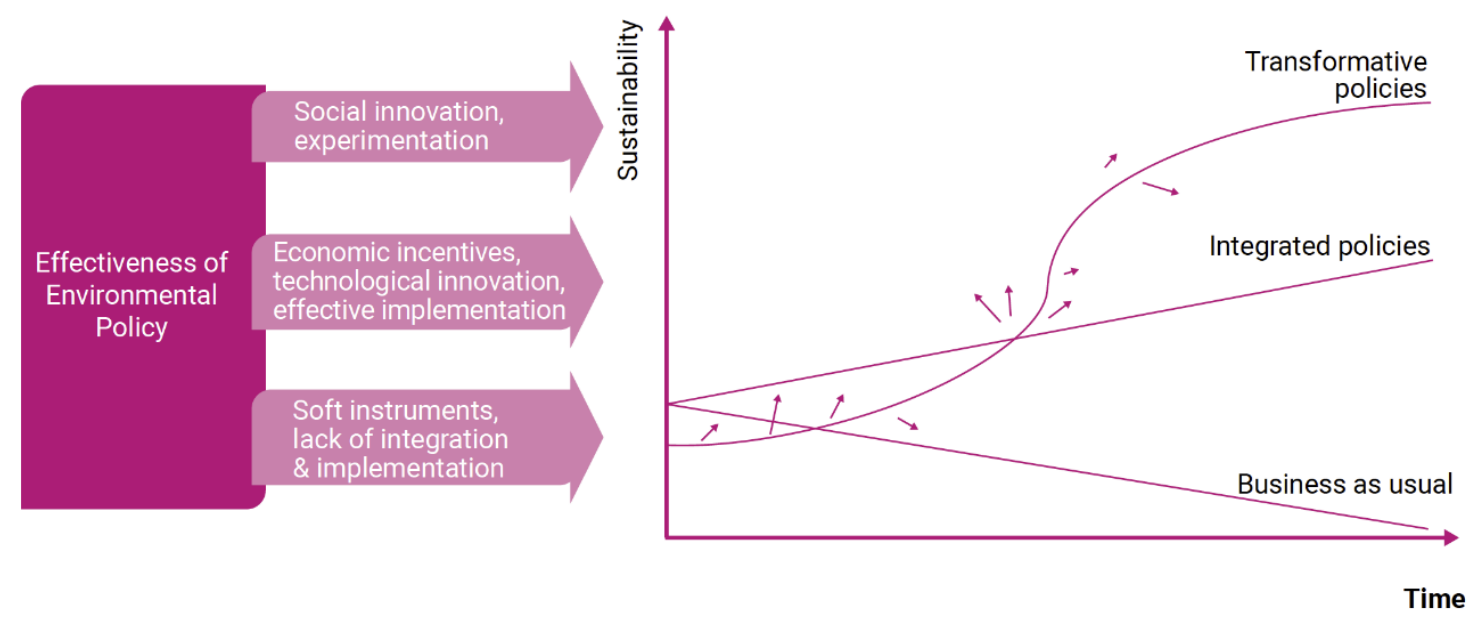

Source: UNEP 2019a, pp.583

The potentials, but also limitations of policies to support bottom up transformative policies are reflected in the GEO-6 assessment as shown in the graph above. The report demonstrates a high level of social innovation around the globe, with a high potential for transformation, but little consideration in current policy making. Current policies and business-as-usual are not sufficient to effectively address the drivers of environmental change. An innovation-oriented, integrated approach, which introduces effective and ambitious environmental policies, provides economic incentives and promotes innovation, is necessary. This should be combined with a transformative approach that encourages and supports environmentally directed bottom-up innovation, including social and institutional innovation. Policies deriving from a transformative approach are experimental and open ended. Given the complexity of socio-technical systems and the constraints on ambitious top-down steering, a transformative approach could be complementary to an integrated policy approach, and seems necessary for the systemic change required adequately to respond to environmental challenges. 


\section{References}

Adelle, C. and Weiland, S. (2012). Policy assessment: The state of the art. Impact assessment and project appraisal 30(1), pp. 25-33. https://doi.org/10.1080/14615517.2012.663256

Adelle, C., Weiland, S., Dick, J., González Olivo, D., Marquardt, J., Rots, G. et al. (2016). Regulatory impact assessment: A survey of selected developing and emerging economies. Public money \& management 36(2), pp. 89-96. https://doi.org/10.1080/09540962.2016.1118930.

Bauknecht, D., Heinemann, C., Stronzik, M., \& Schmitt, S. (2015). Austesten von regulatorischen Innovationen - das Instrument der Regulatorischen Innovationszone. Energiewirtschaftliche Tagesfragen, 65(7).

Baumgartner, F., \& Jones, B. (2009). Agendas and instability in American politics. Chicago: Chicago UP.

Brand, U. (2016): "Transformation" as a new critical orthodoxy. The Strategic Use of the Term "Transformation" does not prevent multiple crisis. In: GAIA 25 (1), S. 23-27.

Busch, P.-O. and Jörgens, H. (2005), International patterns of environmental policy change and convergence. Eur. Env., 15: 80-101. Doi:10.1002/eet.374

Cairney, P. (2013). Standing on the Shoulders of Giants: How Do We Combine the Insights of Multiple Theories in Public Policy Studies?. Policy Studies Journal, 41(1), pp. 1-21. https://doi.org/10.1111/psj.12000

Chataway, J., Daniels, C., Kanger, L., Ramirez, M., Schot, J., \& Steinmueller, E. (2017). Developing and Enacting Transformative Innovation Policy. A comparative Study. Retrieved from http://www.johanschot.com/wordpress/wp-content/uploads/2017/06/Developing-andenacting-Transformative-Innovation-Policy-A-Comparative-Study-FINAL-DRAFT.pdf

Dimitropoulos, A., Oueslati W. and Sintek C. (2016). The Rebound Effect in Road Transport. A Metaanalysis of Empirical Studies. OECD Environment Working Papers.

Emerson, K., \& Baldwin, E. (2019). Effectiveness in NEPA decision making: in search of evidence and theory. Journal of Environmental Policy \& Planning, 21(4), 427-443.

https://doi.org/10.1080/1523908X.2019.1615421

Flanagan, K., Uyarra, E. and Laranja, M. (2011). Reconceptualising the 'policy mix' for innovation. Research policy 40(5), 702-713.

https://doi.org/10.1016/j.respol.2011.02.005.

Geels, F. W. (2002). Technological transitions as evolutionary reconfiguration processes: a multi-level perspective and a case-study. Research Policy, 31(8-9), pp. 1257-1274. https://doi.org/10.1016/S0048-7333(02)00062-8

Geels, F. W., \& Kemp, R. (2012). The multi-level perspective as a new perspective for studying sociotechnical transitions. In F. W. Geels, R. Kemp, G. Dudley, \& G. Lyons (Eds.), Automobility in Transition? A Socio-Technical Analysis of Sustainable Transport. London: Routledge

Grantham Research Institute on Climate Change and the Environment 2017 
Grießhammer, R.; Brohmann, B. (2016). Wie Transformationen und gesellschaftliche Innovationen gelingen können. Transformationsstrategien und Models of Change für nachhaltigen gesellschaftlichen Wandel. Baden-Baden: Nomos.

Hall, P. (1993). Policy paradigms, social learning, and the state. Comparative Politics, 25(3), pp. 27593.

Heyen, D. A., Hermwille, L., Wehnert, T. (2017). Out of the Comfort Zone! Governing the Exnovation of Unsustainable Technologies and Practives. Gaia, 26(4), pp. 326-331. https://doi.org/10.14512/gaia.26.4.9

Howlett, M. P., \& Cuenca, J. S. (2017). The use of indicators in environmental policy appraisal: lessons from the design and evolution of water security policy measures. Journal of Environmental Policy \& Planning, 19(2), 229-243. https://doi.org/10.1080/1523908X.2016.1207507

Huttunen, S. (2015). Farming Practices and Experienced Policy Coherence in Agri-environmental Policies: The Case of Land Clearing in Finland. Journal of Environmental Policy \& Planning, 17(5), 573-592. https://doi.org/10.1080/1523908X.2014.1003348

ILO 2020: List of Green jobs assessments https://www.ilo.org/global/topics/greenjobs/publications/assessments/lang_en/index.htm

Jacob, K., Graaf, L., Wolff, F., \& Heyen, D. A. (2020). Transformative Umweltpolitik: Ansätze zur Förderung gesellschaftlichen Wandels. Dessau UBA Texte.

Jacob, K., Weiland, S., Ferretti, J., Wascher, D. and Chodorowska, D. (2011). Integrating the Environment in Regulatory Impact Assessments. Paris: Organization for Economic Cooperation and Development. https://www.oecd.org/gov/regulatorypolicy/Integrating\%20RIA\%20in\%20Decision\%20Making.pdf.

Jänicke, M., \& Jacob, K. (2013). A Third Industrial Revolution? In B. Siebenhüner, M. Arnold, K. Eisenack, \& K. Jacob (Eds.), Long Term Governance for Social Ecological Change, pp. 47-70. London and New York.

Jänicke, M., \& Rennings, K. (2011). Ecosystem dynamics: The principle of Co-Evolution and Success Stories from Climate Policy. International Journal of Technology Policy and Management, 11(3/4), pp. 198-219. https://doi.org/10.1504/IJTPM.2011.042084

John, B.; Withycombe Keeler, L.; Wiek, A.; Lang, D. I. (2015). How much 16ustainability substance is in urban visions? An analysis of visioning projects in urban planning. Cities, 48, pp. 86-98. https://doi.org/10.1016/j.cities.2015.06.001

Kemp, R. and Pontoglio, S. (2011). The innovation effects of environmental policy instruments-A typical case of the blind men and the elephant? Ecological Economics, 72, pp. 28-36. https://doi.org/10.1016/j.ecolecon.2011.09.014.

Kingdon, J. W. (1995). Agendas, Alternatives and Public Policies, $2^{\text {nd }}$ edition. New York: Harper \& Collins.

Knaggård, Å. (2014). What do policy-makers do with scientific uncertainty? The incremental character of Swedish climate change policy-making. Policy Studies, 35(1), pp. 22-39. https://doi.org/10.1080/01442872.2013.804175.

Kondratieff, N. D. (1926). Die langen Wellen der Konjunktur. Archiv Für Sozialwissenschaften Und Sozialpolitik, 56, pp. 573-609. 
Kostka, G., \& Mol, A. P. J. (2013). Implementation and Participation in China's Local Environmental Politics: Challenges and Innovations. Journal of Environmental Policy \& Planning, 15(1), 3-16. https://doi.org/10.1080/1523908X.2013.763629

Kowarsch, M. (2016). A Pragmatist Orientation for the Social Sciences in Climate Policy. How to Make Integrated Economic Assessments Serve Society. Berlin: Springer.

Lindberg, H. (2013). Knowledge and Policy Change. Cambridge Scholars Publishing, pp. 62-88.

Lindblom, C. E. (1959). The Science of "Muddling Through." Public Administration Review, 19(2), pp. 79-88. https://doi.org/10.2307/973677.

Loorbach, D. (2010): Transition Management for Sustainable Development: A Prescriptive, ComplexityBased Governance Framework. Governance: An International Journal of Policy, Administration, and Institutions, 23 (1), pp. 161-183.

Mayntz, R., \& Scharpf, F. W. (1995). Der Ansatz des akteurzentrierten Institutionalismus. Gesellschaftliche Selbstregelung Und Politische Steuerung, Schriften Des Max-Planck-Instituts Für Gesellschaftsforschung, 23, pp. 39-72. https://doi.org/292.

Maeße, J. (2013). Ökonomie, Diskurs, Regierung. Globale Politische Ökonomie. https://doi.org/10.1007/978-3-658-01294-6

Meadowcroft, J. (2007). Who is in Charge here? Governance for Sustainable Development in a Complex World*. Journal of Environmental Policy \& Planning, 9(3-4), 299-314. https://doi.org/10.1080/15239080701631544

Meadowcroft, J., \& Steurer, R. (2018). Assessment practices in the policy and politics cycles: a contribution to reflexive governance for sustainable development? Journal of Environmental Policy \& Planning, 20(6), 734-751. https://doi.org/10.1080/1523908X.2013.829750

Mickwitz, P., Aix, F., Beck, S., Carss, D., Ferrand, N., Görg, C. et al. (2009). Climate Policy Integration, Coherence and Governance. PEER Report. Helsinki: Partnership for European Environmental Research. http://library.wur.nl/WebQuery/wurpubs/fulltext/3987.

Pomeranz, E. F., \& Decker, D. J. (2018). Designing regional-level stakeholder engagement processes: striving for good governance while meeting the challenges of scale. Journal of Environmental Policy \& Planning, 20(4), 403-418. https://doi.org/10.1080/1523908X.2017.1417119

Pomeranz, E. F., \& Stedman, R. C. (2020). Measuring good governance: piloting an instrument for evaluating good governance principles. Journal of Environmental Policy \& Planning, 22(3), 428440. https://doi.org/10.1080/1523908X.2020.1753181

Radaelli, C.M. (2009). Measuring policy learning: Regulatory impact assessment in Europe. Journal of European Public Policy 16(8), pp. 1145-1164. https://doi.org/10.1080/13501760903332647.

Renewable Energy Policy Network for the $21^{\text {st }}$ Century (REN21). (2017). Renewables 2017 Global Status Report.

Rennings, Klaus (2014): Der mikro-ökonomische Rebound Effekt. Ergebnisse eines inter- und transdisziplinären Forschungsprojekts. Vortrag auf der Green Economy Konferenz des BMBF 18.11.2014. 
Schot, J., \& Geel, F. W. (2008). Strategic niche management and sustainable innovation journeys: theory, findings, research agenda, and policy. Technology Analysis \& Strategic Management, 20(5), pp. 537-554. https://doi.org/10.1080/09537320802292651

Schubert, U., \& Sedlacek, S. (2005). The structure of environmental policy and environmentorientated technology policy signals for environment-orientated innovation. Journal of Environmental Policy \& Planning, 7(4), 317-339. https://doi.org/10.1080/15239080500441111

Schumpeter, J. A. (1942). Capitalism, Socialism, and Democracy. New York, London: Harper \& Brothers Semmling, E., Peters, A., Marth, H., Kahlenborn, W., \& Haan, P. de. (2015). Rebound-Effekte: Ihre Bedeutung für die Umweltpolitik. Dessau.

Sachverständigenrat für Umweltfragen (SRU) (2016): Umweltgutachten 2016. Impulse für eine integrative Umweltpolitik. Hg. v. SRU. Online verfügbar unter http://www.umweltrat.de/SharedDocs/Downloads/DE/01_Umweltgutachten/2016_Umweltgutacht en_HD.html.

United Nations Environment Programme (2011). Towards a Green Economy: Pathways to Sustainable Development and Poverty Eradication.

United Nations Environment Programme (2019a). Global Environmental Outlook GEO-6. Healthy Planet, Healthy People.

United Nations Environment Programme (2019b). Global Environmental Outlook GEO-6. Summary for Policymakers.

van der Heijden, J. (2015). What 'Works' in Environmental Policy-Design? Lessons from Experiments in the Australian and Dutch Building Sectors. Journal of Environmental Policy \& Planning, 17(1), 44-64. https://doi.org/10.1080/1523908X.2014.886504

WBGU. (2011). Welt im Wandel Gesellschaftsvertrag für eine Große Transformation. Berlin.

Welzer, H., \& Leggewie, C. (2010). Cultural and societal requirements of The Great Transformations. Journal of Renewable and Sustainable Energy, 2(3).

Wiek, A.; Iwaniec, D (2014). Quality criteria for visions and visioning in sustainability science. Sustain Sci, 9, pp. 497-512. https://doi.org/10.1007/s11625-013-0208-6

Wolff, F., Schönherr, N., \& Heyen, D. A. (2017). Effects and success factors of sustainable consumption policy instruments: a comparative assessment across Europe. Journal of Environmental Policy \& Planning, 19(4), 457-472. https://doi.org/10.1080/1523908X.2016.1254035

Yin, H. and Powers, N. (2010). Do state renewable portfolio standards promote in-state renewable generation? Energy Policy 38(2), 1140-1149. https://doi.org/10.1016/i.enpol.2009.10.067. 